\title{
Black rice cultivar from Java Island of Indonesia revealed genomic, proteomic, and anthocyanin nutritional value
}

\author{
Dewi Ratih Tirto Sari1,2, Atchara Paemanee, Sittiruk Roytrakul4, James R. Ketudat Cairns ${ }^{5}$, \\ Anna Safitri1,6 and Fatchiyah Fatchiyah ${ }^{1,2 \square}$ \\ 'Research Center of Smart Molecule of Natural Genetics Resources, Brawijaya University, Indonesia; 2Department of Biology, Faculty of Math- \\ ematics and Natural Sciences, Brawijaya University, Indonesia; ${ }^{3}$ National OMICS Center, National Science and Development Agency, Pathum \\ Thani, Thailand; 4Functional Ingredients and Food Innovation Research Group, National Center for Genetic Engineering and Biotechnology, \\ National Science and Technology Development Agency, Pathum Thani, Thailand; 5 School of Chemistry, Institute of Science, \& Center for Bio- \\ molecular Structure, Function and Application, Suranaree University of Technology, Nakhon Ratchasima, Thailand; ${ }^{6}$ Department of Chemistry, \\ Faculty of Mathematics and Natural Sciences, Brawijaya University, Indonesia
}

Black rice is considered to be functional food containing anthocyanins as bioactive compounds. This study examined the genomic and proteomic patterns in local black rice from Java Island, Indonesia, with attention to the mechanism of anthocyanin synthesis. Three kinds of black rice from Java Island, including black rice from East Java (BREJ), black rice from Central Java (BRCJ), and black rice from West Java (BRWJ), were studied in comparison to white rice (WREJ) and red rice (RREJ). Genomic profiling was done by simple sequence repeat (SSR) analysis, and sequencing of red coleoptile $(R c)$ and glycosyltransferase (GT) genes, followed by in silico analysis. Total anthocyanin was investigated by ultra-high performance liquid chromatography- diode array detector (UHPLC-DAD). The proteomic profiles were determined by liquid-chromatography and mass spectrometry of tryptic peptides. The SSR profiles showed a specific band in each black rice variant. The $R c$ gene exon-2 sequences were similar in the three black rice cultivars. The GT gene sequence was identified as a new variant that correlates with the purple stem, leaf, bran, and whole grain morphology seen exclusively in the BRWJ cultivar. The anthocyanin composition in Java black rice is diverse. The highest cyanidin level was seen in BRWJ and the highest level of peonidin-3-O-glucoside in BREJ. Proteomic profiling of the black rice cultivars demonstrated that the expression of proteins that might be related to the levels of anthocyanin synthesis varied. These studies conclude that the genomic, proteomic and anthocyanins composition of Java black rice cultivars may be used the improvement of their functional nutrition values.

Keyword: anthocyanins, black rice, genomic, glycosyltransferase, proteomic

Received: 08 June, 2020; revised: 21 January, 2021; accepted: 22 January, 2021; available on-line: 07 March, 2021

『e-mail: fatchiya@ub.ac.id

Acknowledgements of Financial Support: This research has been financially supported by PMDSU research grant (2018-2020) and PKPI program (2020) from the Ministry of Research and Technology /National Agency for Research and Innovation, and RISPROPRN-LPDP National Research Grant from the Ministry of Research and Technology - BRIN and Ministry of Finance, Republic of Indonesia (2020-2024). JRKC acknowledges the financial support from the National Research Council of Thailand (grant IRN62W0004) and Suranaree University of Technology.

Abbreviations: NS, anthocyanin synthase; ANR, anthocyanin reductase; bHLH, basic helix loop helix; BREJ, black rice from East Java; BRCJ, black rice from Central Java province; BRWJ, black rice from West Java province; $C$, coding sequence; CHS, chalcone synthase; $\mathrm{CHI}$, chalcone isomerase; CTAB, hexadecyltrimethylammonium bromide; $D A D$, diode array detector; del, deletion; $D F R$, dihydroflavonol reductase; DNA, deoxyribonucleic acid; $F 3 H$, flavanone3-hydroxylase; GT, glycosyltransferase; ins, insertion; MBW, MYBbHLH-WD40; MS, Mass spectrometry; MS/MS, tandem mass spectrometry; MYB, myeloblastosis transcription factor; OsPAL, Oryza sativa phenylalanine ammonia lyase, OsCHS, Oryza sativa chalcone synthase, Os3GT, Oryza sativa 3-glycosyltransferase; OsGST, Oryza sativa glutathione-S-transferase; OsLDOX, Oryza sativa leucoanthocyanidin oxidase; OsMT, Oryza sativa methyltransferase; OsWD40, Oryza sativa beta transducing; PAL, phenylalanine ammonia lyase; $\mathrm{Rc}$, red coleoptile; RM, Rice marker; RREJ, red rice East Java province; SNPs; single nucleotide polymorphisms; SSR, Simple sequence repeat; subs, substitution; UPGMA, unweighted pair-group method with arithmetical average; UHPLC, ultra-high performance liquid chromatography; WREJ, white rice East Java province.

\section{INTRODUCTION}

Pigmented rice, including brown, red, and black rice (Oryza sativa L.) has a high nutritional value, including high amounts of amino acids and beneficial phytochemical compounds (Sivamaruthi et al., 2018; Fatchiyah et al., 2020a). For instance, previous studies have reported that bioactive compounds in pigmented rice extract have antioxidant (Anisimoviené et al., 2013), anti-inflammatory (Sari et al., 2019a), anti-diabetes (Azzini et al., 2017), anti-obesity (Thompson et al., 2016; Yan \& Zheng, 2017), and anti-apoptosis (Sari et al., 2020a) activities. The bioactive compounds in pigmented rice include the anthocyanins responsible for rice pigmentation (Hou et al., 2013). Anthocyanins accumulate in various rice tissues such as leaves, stems, anthers, and grains (Zheng et al., 2019; Zaidi et al., 2019; Prasad et al., 2019). Samyor and others (Samyor et al., 2017) identified cyanidin, cyanidin3-O-glucoside, peonidin-3-O-glucoside, and peonidin in black-purple rice grains, while Zheng and others (Zheng et al., 2019) reported anthocyanin content in black rice leaves.

Anthocyanins are influenced by several environmental factors and regulated by genetic variability and transcription factors (Chin et al., 2016; Zheng et al., 2019). Genes related to anthocyanins' production that have been well studied include structural genes encoding the enzymes: phenylalanine ammonia-lyase (PAL), chalcone synthase $(C H S)$, chalcone isomerase $(C H I)$, anthocyanin synthase (ANS), flavonol-3-hydroxylase $(\mathrm{F} 3 \mathrm{H})$, dihydroflavonol reductase (DFR), and anthocyanin reductase (ANR) (Chen et al., 2013). Furthermore, these anthocyanin synthesis genes are regulated by several transcription factors, such as MYB, MYC, Rc, and C-S-A (Himi \& Taketa, 2015). 
Red coleoptile $(R c)$ is a gene encoding a basic helix loop helix (bHLH) transcription factor protein mapped on chromosome 7 ( $\mathrm{Xu}$ et al., 2015). The $\mathrm{R} c$ gene is associated with the rice domestication process. The $\mathrm{R} c$ gene has seven exons, and a mutation in $\mathrm{R} c$ exon 7 causes a frameshift in the open reading frame, thereby producing a dysfunctional bHLH protein to switch off anthocyanin gene expression in white rice (Furukawa et al., 2006; Sweeney et al., 2006; Zhu et al., 2019). However, mutations and variations in other exons of the $R c$ gene are less well characterized. In their functional forms, bHLH proteins with WD40 and MYB form an MBW (MYB, bHLH, and WD40) complex to activate anthocyanin gene expression, including that of DFR, LAR, ANS, ANR, and glycosyltransferase (GT) (Albert et al., 2014).

The GT gene encodes the glycosyltransferase protein that transfers sugar residues to anthocyanidins (Chen et al., 2016). Glycosyltransferases constitute a large group of proteins, which have several functions in plant metabolism and physiology (Cao et al., 2008). The GT genes contribute to rice anther growth and development (Moon et al., 2013), hormone inactivation (Luang et al., 2013), structural polysaccharide formation, and anthocyanin biosynthesis (Sun et al., 2016; Wang et al., 2018; Liu et al., 2020). In the anthocyanin synthesis, glycosyltransferases add a sugar group onto carbon number three of anthocyanidin. Glycosylation stabilizes anthocyanins, allows them to be stored in the vacuole, and increases anthocyanin solubility in water (Wang et al., 2018). The glycosyltransferase enzymes have been widely studied in many plants. Nevertheless, the genes that encode anthocyanin glycosyltransferases in rice have not been described.

Genomic variability also influences the anthocyanin content in rice and correlates with rice cultivars. Genomic variability could be assessed by targeting simple sequence repeats (SSR), which present some advantages over other markers. The SSR markers are highly suitable for genetic diversity analysis with high reproducibility (Chen et al., 2013). SSR markers were used to effectively assess the genomic variability of African cultivated and wild-type rice (Chen et al., 2017). Both of these rice populations showed SSR allele polymorphisms that separated them well. Park and others (Park et al., 2019) used sixteen selective SSR primers to evaluate several black-purple and red rice cultivars' genetic diversity. The cultivars separated into several clades that associated with their morphology and the region where they were grown. Differential gene expression might alter the proteomic profiles and anthocyanin accumulation in pigmented rice. Proteomic studies have been conducted to assess the differences in protein expression due to cultivar differences and environmental effects. Maksup and others (Maksup et al., 2017) compared the proteomic profile of germinated and non-germinated brown rice, in which germinated brown rice exhibited higher protein expression than nongerminated brown rice. A previous study reported that at least six proteins related to anthocyanins were expressed in black and not white glutinous rice leaves (Phonsakhan \& Kong-Ngern, 2015). Using sodium dodecyl sulfatepolyacrylamide gel electrophoresis (SDS-PAGE) with Coomassie Brilliant Blue (CBB) staining, Sari and others (Sari et al., 2019b) detected specific protein bands in black rice seeds from Java, while those proteins were not detected in white or red rice. However, SDS-PAGE with $\mathrm{CBB}$ staining is not the most sensitive method for measurement of protein expression levels. In the current study, an ultra-high-resolution time-of-flight liquid chromatography-mass spectrometry (UHR-ToF LC-MS) of tryptic peptides was used to identify and quantify protein expression in five varieties of pigmented and nonpigmented rice from Java Island.

Hence, to evaluate the differences between Javanese pigmented and non-pigmented rice, we assessed the genomic variability using SSR markers and partial sequencing of genes related to anthocyanin synthesis (Rc and GT genes), examined proteomic profiles using UHR-TOF-LC-MS, and measured their anthocyanins components.

\section{MATERIALS AND METHODS}

The white rice cultivar Mentik Wangi (WREJ), red rice cultivar Mentik (RREJ), black rice cultivar NTT local (N790) (BREJ) from Malang, East Java, black rice cultivar Melik from Semarang, Central Java (BRCJ), and black rice Toraja local from Sukabumi, West Java (BRWJ) were used in this study. Peonidin ( $\geq 97 \%$ purity, HPLC grade, Cat. $0906 \mathrm{~S}$ ), cyanidin ( $\geq 96 \%$ purity, HPLC grade, Cat. 0909 S), cyanidin-3-O-glucoside ( $\geq 96 \%$ purity, HPLC grade, Cat. $0915 \mathrm{~S})$, and peonidin-3-O-glucoside $(\geq 95 \%$ purity, HPLC grade, Cat. 0929 S) were acquired from Extrasynthese (France). The ethical clearance committee of Brawijaya University approved all experiments in this study, with approval number 896-KEP-UB.

\section{Genomic analysis of pigmented rice from Java Island}

Genomic DNA was extracted from 20-day-old seedling leaves of five cultivars of pigmented rice by the hexadecyltrimethylammonium bromide (CTAB) method (Fatchiyah et al., 2011). DNA concentration was measured with a NanoDrop spectrophotometer (ND-1000, NanoDrop Inc., USA). DNA quality was checked by running it on a $0.8 \%$ agarose gel in $1 \times$ TBE buffer (Tris base, boric acid, and EDTA pH 8.3 ) at $100 \mathrm{~V}$ for $30 \mathrm{~min}$, and then the gel was observed on a UV transilluminator. PCR was conducted to analyze the genomic variability of pigmented rice. The set of primers used for the $S S R$ was from Chen and others (Chen et al., 2017), while the Rc gene (KX549256) and the GT gene (XM015777298.2) primers were designed to bind at specific sites (Table S1 at Supplementary Data at https://ojs.ptbioch.edu.pl/ index.php/abp). Fifty microliters of the PCR reaction mix consisted of $25 \mu \mathrm{L}$ of $2 \times$ GoTaq $^{\circledR}$ Green Master Mix (Promega, Cat.M712), $0.2 \mu \mathrm{M}$ of each primer, $50 \mathrm{ng} / \mu \mathrm{L}$ genomic DNA, and deionized water. The PCR program was set to $95^{\circ} \mathrm{C}$ for $30 \mathrm{~s}, 51-57^{\circ} \mathrm{C}$ for $30 \mathrm{~s}$, and extension at $72^{\circ} \mathrm{C}$ for $45 \mathrm{~s}$, for 35 cycles. The $R c$ and $G T$ genes were separated by electrophoresis using $1.5 \%$ agarose gels, while the $S S R$ profile was done using $5 \%$ polyacrylamide non-denaturing gels. All DNA gels were stained with ethidium bromide and then visualized on a UV transilluminator (BioRad, Cat. No 161-0433).

\section{Total anthocyanin extraction, purification and analysis using UHPLC-DAD of pigmented rice from Java Island}

The pigmented rice grains were ground to a fine powder and extracted with $0.1 \% \mathrm{HCl}$ in methanol (Huang \& Lai, 2016). Anthocyanin extracts were concentrated on a rotary evaporator (Heidolph, Germany) at $40^{\circ} \mathrm{C}$ and cooled to $4^{\circ} \mathrm{C}$. Total anthocyanin extracts were partially purified using Sephadex ${ }^{\circledR}$ LH-20 chromatography in methanol followed by silica gel column chromatography (Zhang et al., 2018). The silica gel was 
eluted with a gradient of $20-100 \%$ of ethyl acetate in $\mathrm{n}$-hexane followed by $30-100 \%$ methanol in dichloromethane. Pigmented rice fractions were separated by thin-layer chromatography (TLC) with n-butanol: acetic acid: water (3:1:1) as mobile phase and silica gel 60 $\mathrm{F}_{254}$ plates (Merck; Cat. No 1.05554.0007) as stationary phase (Priya, et al., 2013). Based on the presence of anthocyanin spots on the TLC plates, fraction 6 of RREJ (RREJ F6), fraction 5 of BREJ (BREJ F5), fraction 9 of BRCJ (BRCJ F9), and fraction 15 of BRWJ (BRWJ F15) from the silica gel column chromatography were analyzed using ultra-high-performance liquid chromatography with a diode array detector (UHPLC-DAD, Agilent 1100 series). Two microliters of $0.5 \mathrm{mg} / \mathrm{ml}$ filtered fractions were injected into the UHPLC and separated through a Zorbax SB-C18 2.1×150 mm 1.8-micron column (Agilent, USA; Part Number:5188-5328). Solution A $(0.2 \%$ formic acid) and solution B (acetonitrile) were used as mobile phases. The flow rate was $0.2 \mathrm{ml} / \mathrm{min}$, and the gradient began in $100 \% \mathrm{~A}$, then 0-2 $\min 0-5 \% \mathrm{~B} ; 2-13 \min 5-50 \% \mathrm{~B} ; 13-14 \mathrm{~min} 50-$ $70 \% \mathrm{~B} ; 14-16 \min 70-100 \% \mathrm{~B}$ and $16-25 \min 100 \% \mathrm{~B}$. Anthocyanin peaks were detected by diode array detector (DAD) (1260 Infinity II Diode Array Detector HS, Agilent) at the wavelength $520 \mathrm{~nm}$.

\section{Extraction and determination of total protein from pigmented rice from Java Island}

Total protein was extracted from the ground rice seeds in Tris- $\mathrm{HCl}$ buffer followed by $10 \%$ trichloroacetic acid (TCA)/acetone precipitation (Wang et al., 2016). Approximately $500 \mathrm{mg}$ of pigmented rice powder was extracted with lysis buffer solution $(20 \mathrm{mM}$ Tris- $\mathrm{HCl} \mathrm{pH} 8.0,2 \% \mathrm{NP}-40,1 \mathrm{mM}$ of EDTA) and centrifuged at $10,000 \times \mathrm{g}, 15 \mathrm{~min}$. The supernatant was mixed with $10 \% \mathrm{TCA}$ in cold acetone and incubated overnight at $-20^{\circ} \mathrm{C}$. The insoluble protein was washed with cold acetone five times and air-dried. The dried proteins were re-suspended with $0.5 \%$ SDS in Tris- $\mathrm{HCl}$ buffer, and the protein concentration was measured by the Lowry method with bovine serum albumin as a protein standard (Shen, 2019).

\section{Tryptic digestion and analysis using Impact II UHR-TOF LC-MS}

Five micrograms of crude protein were reduced using $5 \mathrm{mM}$ dithiothreitol (DT'T) in $10 \mathrm{mM}$ ammonium bicarbonate at $60^{\circ} \mathrm{C}$ for an hour and alkylated using 15 $\mathrm{mM}$ iodoacetamide (IAA) in $10 \mathrm{mM}$ ammonium bicarbonate at room temperature for $45 \mathrm{~min}$ in the dark. Then, the samples were digested with sequencing grade trypsin (Promega, Germany) at the protein to enzyme ratio of $1: 25$ for 4 hours at $37^{\circ} \mathrm{C}$. The peptides were dried at $30^{\circ} \mathrm{C}$ under vacuum and analyzed on an Impact II UHR-TOF MS System (Bruker Daltonics Ltd., Germany). Pigmented rice peptides were enriched on a C18, $5 \mu \mathrm{m} 100 \AA$ (Thermo Scientific, UK), Pepmap $100,5 \mathrm{~mm} \times 300 \mu \mathrm{m}$ i.d., $\mu$-precolumn and separated on an analytical column $(75 \mu \mathrm{m}$ i.d. $\times 15 \mathrm{~cm})$ packed with Acclaim PepMap RSLC C18 $2 \mu \mathrm{m} 100 \AA$, nanoViper (Thermo Scientific, UK). The gradient system of $5-55 \%$ B over $30 \mathrm{~min}$, with solvent A $(0.1 \%$ formic acid) and solvent B (0.1\% formic acid in $80 \%$ acetonitrile) was used to elute peptides. The flow rate was $0.3 \mu \mathrm{l} / \mathrm{min}$. Mass spectra (MS) and MS/MS spectra were acquired in the positive-ion mode $(\mathrm{m} / \mathrm{z})=150$ 2200 with $1.6 \mathrm{kV}$ of Captive Spray (Compass 1.9 for TOF Series software, Bruker Daltonics).

\section{Proteins quantification and identification}

Mass spectra of peptides were analyzed with MaxQuant 1.6.3.3 software associated with the Andromeda search engine (Tyanova et al., 2015). The peptide search parameters were a maximum of three missed cleavages, $0.07 \mathrm{Da}$ and $0.006 \mathrm{Da}$ as first and main search tolerances, 30 as threshold intensity, trypsin as digesting enzyme, carbamidomethylation of cysteines as a fixed modification, and the oxidation of methionine and acetylation of the protein $\mathrm{N}$-terminus as variable modifications. To identify the proteins, peptides with a minimum of 7 amino acids and at least one unique peptide were required.

\section{Data analysis}

The diagram of total protein in pigmented rice from Java Island was constructed with the Jvenn tool (http:// jvenn.toulouse.inra.fr/app/index.html) and presented as a Venn diagram. A heat map was generated using the online heat-mapper software (http://heatmapper.ca), and the biological functions of each protein were predicted using the protein informatics resource (PIR) database (https://proteininformationresource.org/). Anthocyanin contents were reported as mean \pm standard deviation. All of the experiments were conducted in triplicate and analyzed using either one-way analysis of variance (ANOVA) for cyanidin-3-O-glucoside among three black rice cultivars, or t-test for other anthocyanins between BREJ F5 and BRWJ F15. A p-value of $<0.05$ was considered to be statistically significant. All genomic data were scored with the values 0 for conserved band/sequence, 1 for similarity > variability, and 2 for similarity<variability (Supplementary Data, Table S2). Phylogenetic analyses were done using the Multi-Variate Statistical Package (MVSP) with UPGMA (Unweight pair group method with arithmetic averages) similarity coefficient.

\section{RESULTS}

\section{Genomic characterization of local black rice from Java Island, Indonesia}

In order to evaluate the genomic profiles of three black rice cultivars, the simple sequence repeat (SSR) patterns were assessed based on five percent polyacrylamide gel electrophoresis. A preliminary study identified nine sets of SSR primers that showed polymorphic bands in black rice samples. A total of 74 SSR alleles were identified using nine SSR markers across the five cultivars of rice from Java island, 29 of which were polymorphic (Fig. 1a). The SSR markers produced 100-800 bp bands, and specific bands were seen in three black rice cultivars, as shown in Fig. 1a. We found specific bands in all black rice samples, including RM318 and RM224 markers (both of which are $200 \mathrm{bp}$ ) in BRWJ, RM202 at around $350 \mathrm{bp}$ in BREJ, and RM251 at around 500 bp in BRCJ and 800 bp in BREJ. A 100 bp RM1369 band was observed in BRCJ and BRWJ, and the 120 bp and 200 bp bands from RM223 appeared in the three cultivars of black rice. RM6364 showed a specific band at around 300-400 bp that was only identified in BRWJ, and 200-300 bp bands that were detected in BREJ and BRCJ.

The nucleotide sequences of the $\mathrm{R} c$ and $G T$ genes showed specific variations in the three black rice cultivars from Java island. The $R c$ gene segment from exons 1-2 was amplified to give $990 \mathrm{bp}$ fragment (Fig. 1b-c). 
a
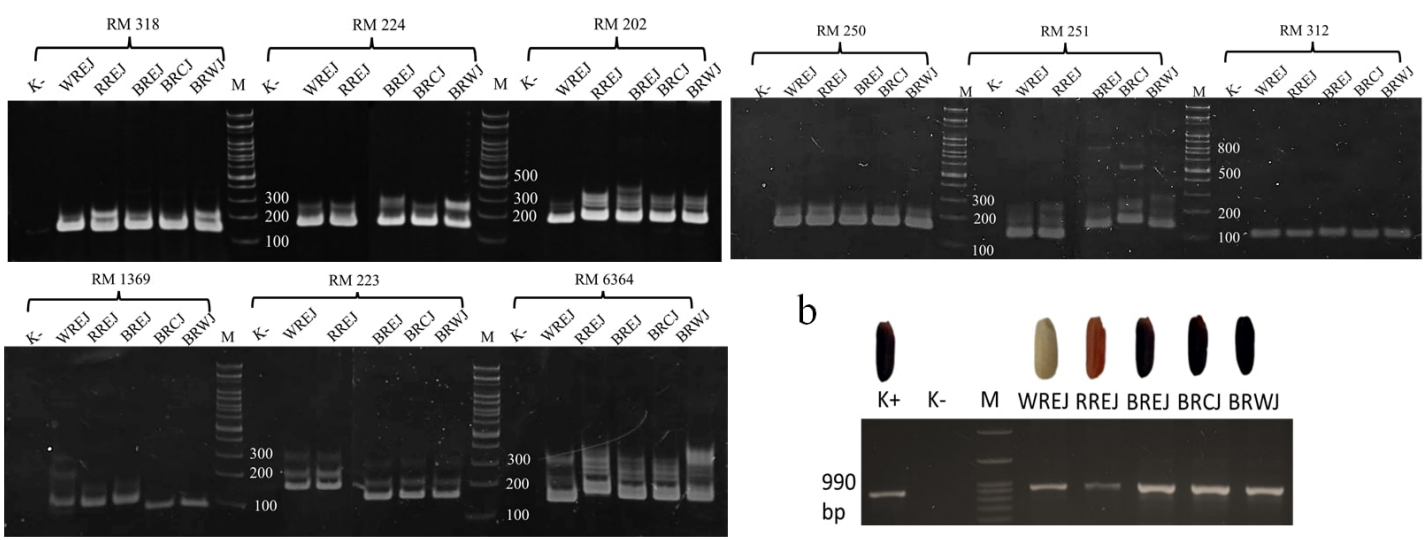

b
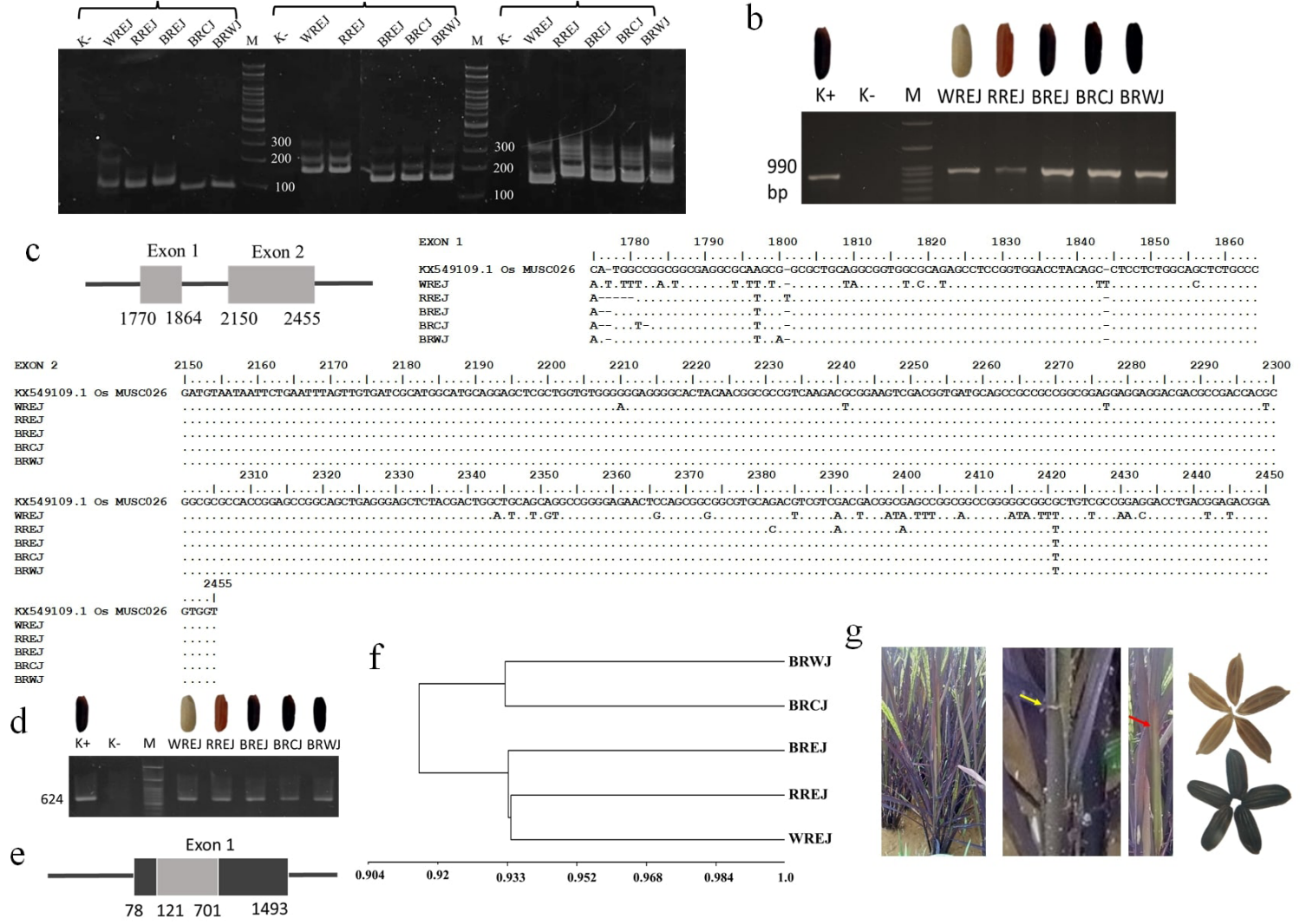

$78121701 \quad 1493$
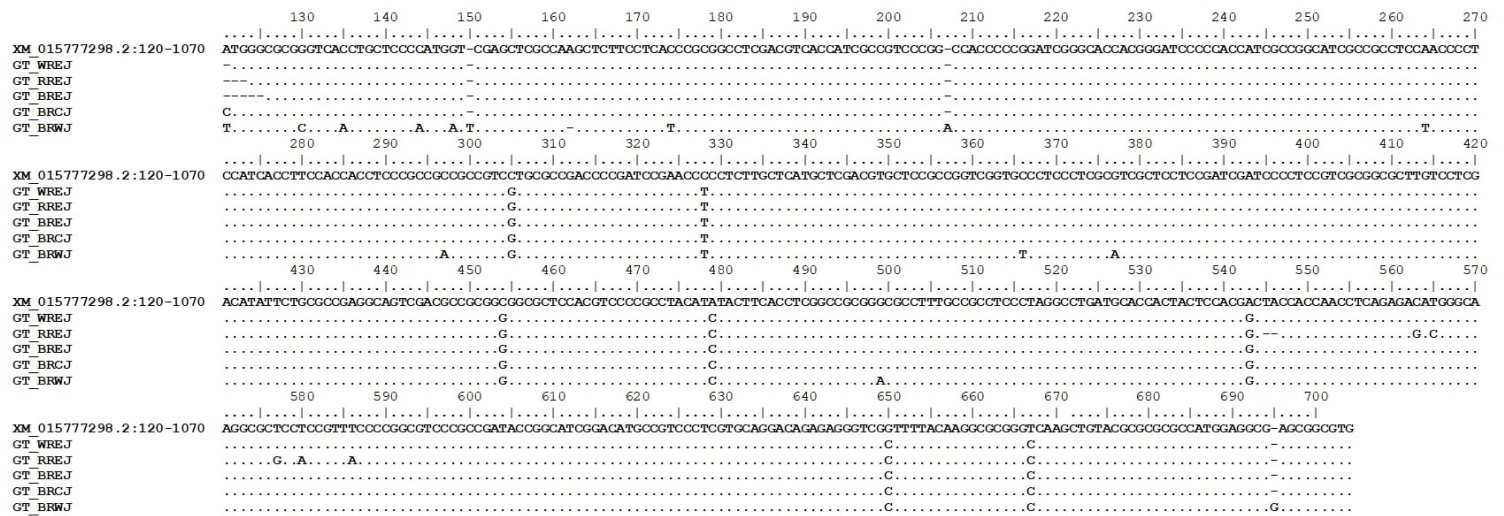

Figure 1. Genomic characterization of local black rice from Java Island using SSR markers and Rc and glycosyltransferase (GT) genes sequencing.

(a) Alleles detected with PCR using nine sets of SSR primers, including RM318, RM224, RM202, RM1369, RM223, RM6364, RM250, RM251, and RM312. (b) PCR product of the Rc gene, (c) Schematic diagram of the Rc gene alignment, including sequenced Rc genes from the studied cultivars and a reference sequence [KX549109.1]. (d) PCR amplification of the GT gene of black rice compared to white and red rice, (e) Schematic diagram of glycosyltransferase (GT) gene and multiple sequence alignment of the GT gene for the five studied cultivars and reference gene [XM015777298.2]. The conserved positions are shown as dots and differences are given with specific letters. (f) Phylogenetic tree of Javanese pigmented rice generated from genomic data (SSR pattern, Rc and GT gene sequences). (g) Morphological characteristics of BRWJ plant: general morphology auricle (yellow arrow), leaf blade (red arrow), and rice grain.

All three cultivars of black rice had a c.1797A $>$ T substitution in the $\mathrm{R} c$ gene exon 1 . Moreover, other mutations were found in $\mathrm{Rc}$ gene exon 1 in BRCJ, namely, a c.1781C $>\mathrm{T}$ substitution and a c.1782delC deletion, while a $1800 \mathrm{G}>\mathrm{A}$ substitution was detected in BRWJ. These particular mutations were not found in black rice hull from Cambodia (gene accession KX549109.1), and showed to be specific for the black rice cultivars from 

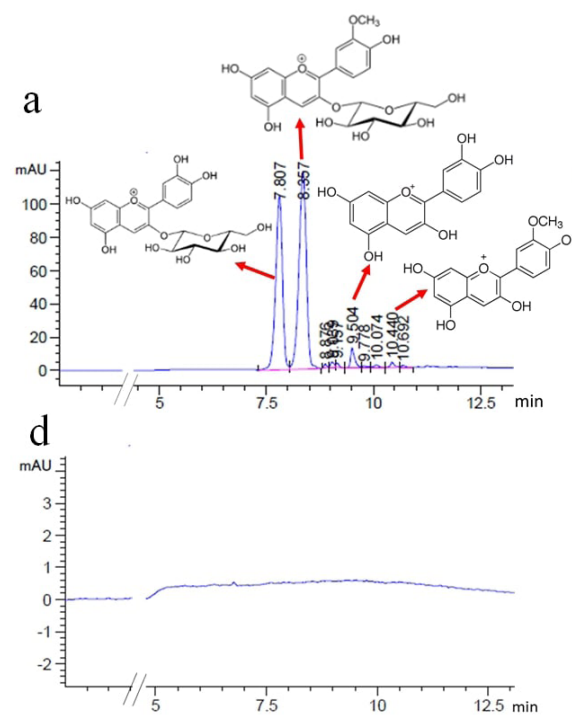

b

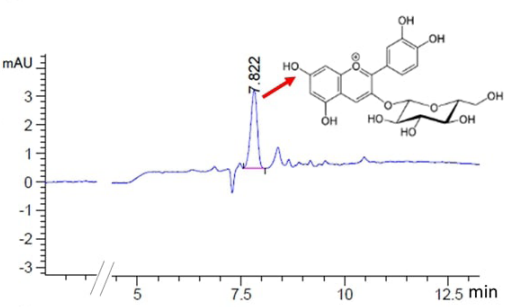

$\mathrm{e}$

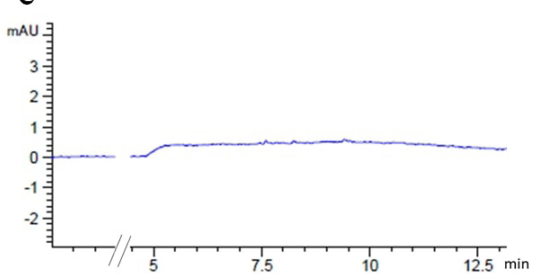

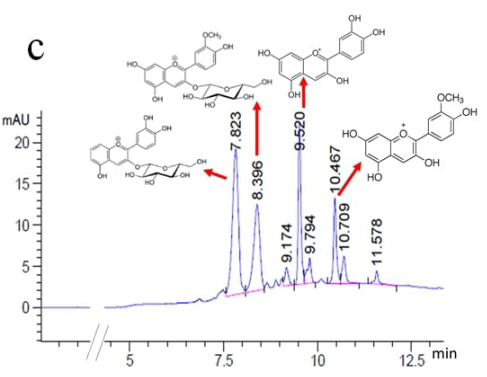

\begin{tabular}{|c|c|c|c|}
\hline \multirow[b]{2}{*}{ Anthocyanins } & \multicolumn{3}{|c|}{ Concentration $(\mu \mathrm{M})$} \\
\hline & BREJ extract fraction F5 & BRCJ extract fraction F9 & $\begin{array}{c}\text { BRWJ extract fraction } \\
\text { F15 }\end{array}$ \\
\hline Cyanidin (RT 9.520) & $40.46 \pm 0.36^{\mathrm{a}}$ & nd & $44.36 \pm 0.44^{b}$ \\
\hline Cyanidin-3-O-glucoside (RT 7.807) & $84.09 \pm 0.04^{b}$ & $2.04 \pm 0.01^{\mathrm{a}}$ & $14.69 \pm 0.28^{\mathrm{ab}}$ \\
\hline Peonidin (RT 10.440) & $10.41 \pm 0.56^{\mathrm{a}}$ & nd & $21.92 \pm 0.81^{\mathbf{b}}$ \\
\hline Peonidin-3-O-glucoside (RT 8.357) & $164.94 \pm 0.03^{\mathrm{a}}$ & nd & $14.18 \pm 0.16^{b}$ \\
\hline
\end{tabular}

Figure 2. Anthocyanins identified by UHPLC-DAD $s$ in black rice from Java compared to white rice and red rice.

The chromatogram and concentration of anthocyanins in (a) BREJ F5, (b) BRCJ F9, (c) BRWJ F15, (d) WREJ, and (e) RREJ F6 extracts. Black rice anthocyanins were determined by UHPLC-DAD detecting absorbance at $520 \mathrm{~nm}$ and their concentration was calculated based on the corresponding standards. Anthocyanins were not detected in the white and red rice varieties. Anthocyanin concentrations are given as mean \pm standard deviation, and different alphabet in the table shows a significant level $(p<0.05)(\mathbf{f})$ comparing each sample.

Java island. The $R c$ gene exon 2 in the three black rice cultivars showed similar sequences, not found in white rice. The GT gene consisted of one exon of 1693 bp, as shown in Fig. 1d. A partial sequence of the GT gene covering $624 \mathrm{bp}$ that encoded an N-terminal region of the glycosyltransferase protein was compared for the black, red, and white rice cultivars (Fig. 1d-e). We found some mutations in the BRWJ GT gene compared to the other cultivars, which included substitutions c.130G $>$ C, c. $135 \mathrm{C}>\mathrm{A}$, c.144C $>$ A, c.148G $>$ A, c.174C $>$ T, c. $264 \mathrm{~A}>\mathrm{T}$, с. $297 \mathrm{C}>\mathrm{A}$, с.366C $>\mathrm{T}$, c. $377 \mathrm{G}>\mathrm{A}$, c. $499 \mathrm{G}>\mathrm{A}$, a c.162delA deletion and the insertions c.150_150ins'T, c.207_208insA, and c.695insG. The mutations observed in the BRWJ GT gene might be unique to this black rice cultivar. This study found several DNA polymorphisms in rice plants from Java island occurring at 305, $328,454,479,543$, and $667 \mathrm{bp}$ compared to the database sequence for black rice japonica. This sequence variation may be specific for the rice from Java Island. The genetic relationship between the three black rice cultivars compared to red rice and white rice is illustrated as a phylogenetic tree in Fig. 1f.

According to the SSR patterns and $\mathrm{R} c$ and GT gene sequences, two black rice cultivars, BRWJ and BRCJ, clustered in one group with a similarity coefficient of 0.935, while black rice cultivar BREJ clustered with red rice and white rice in another group, with a similarity coefficient of 0.936 . Genomic variability analysis showed that BRWJ had a high GT gene sequence variability, and in addition, BRWJ differed in color and morphological traits. BRWJ has purple color in the stem, auricle, leaf blade, bran, and whole grain (Fig. 1g). In comparison, BREJ and BRCJ are purple only in whole grains, primarily in the bran.

\section{Anthocyanin compositions in local Javanese black rice}

The black rice anthocyanins profile was analyzed with UHPLC-DAD and the chromatograph of absorbance at $520 \mathrm{~nm}$ is shown in Fig. 2. Cyanidin-3-O-glucoside was identified in the various fractions of all three cultivars of black rice including F5 in BREJ, F9 in BRCJ, and F15 in BRWJ (Fig. 2a-2c). In BREJ F5 and BRWJ F15, cyanidin, peonidin, and peonidin-3-O-glucoside were found. Interestingly, cyanidin expression was higher in BRWJ F15 than in other cultivars, and peonidin-3-O-glucoside expression was higher in BREJ F5 than in other cultivars.

\section{Proteomic profiling of local black rice from Java island}

When the rice seed proteins were extracted and trypsin - digested, and the resulting peptides analyzed with Impact II UHR-TOF LC-MS, a total of 3434 proteins were identified in the pigmented rice from Java island. The 2316 proteins were conserved in all the three black rice cultivars from Java island. A Venn diagram shown in Fig. 3a compares the identified proteins in three black rice from Java Island, red rice and white rice (Fig. 3a). Among the black rice cultivars, the most proteins were identified in BREJ, followed by BRWJ and BRCJ. A group of proteins was identified only in a certain rice 

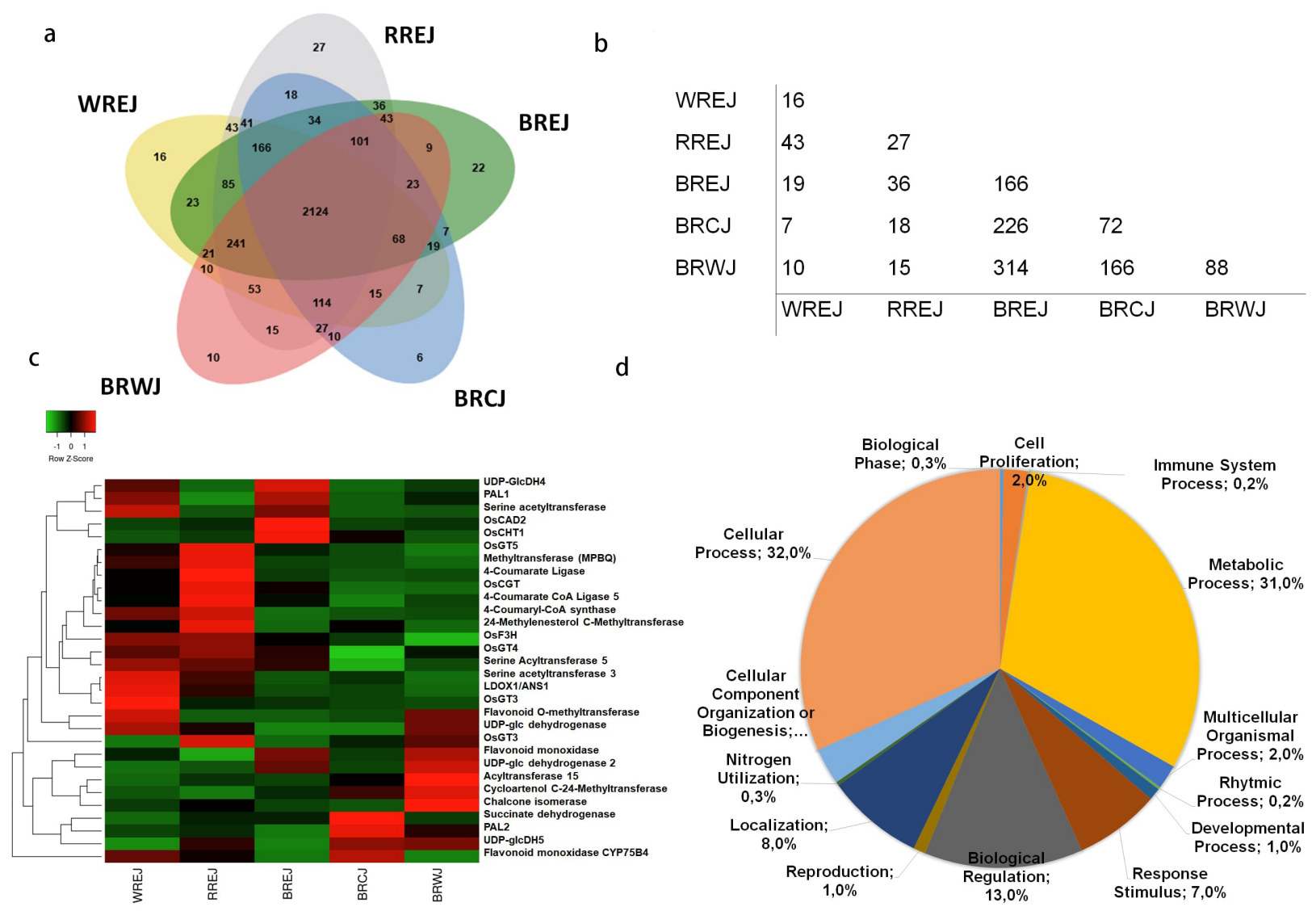

Figure 3. Protein profiling and expression levels of black rice from Java island.

The analysis was based on shotgun proteomics with Impact II UHR-TOF LC-MS. (a) Venn diagram of the common proteins identified in the rice cultivars, (b) The Number of common identified proteins in the black rice cultivars from Java island and the controls: white (WREJ) and red rice (RREJ), (c) Heat map of relative levels of proteins associated with anthocyanin biosynthesis, detected in pigmented rice. (d) Pie chart showing the putative biological function of the proteins expressed in Java black rice.

cultivar, including 166 in BREJ, 72 in BRCJ, and 88 in BRWJ. Figure $3 \mathrm{~b}$ shows the numbers of common proteins between different cultivars. Out of 2124 proteins in pigmented rice, black rice BRWJ had 166 proteins in common with BRCJ, and 314 proteins in common with BREJ. Black rice BREJ and BRCJ had 266 proteins in common. In comparison BRWJ had 15 proteins in common with RREJ, and 10 with WREJ.

The relative expression levels of proteins related to anthocyanin biosynthesis in different rice cultivars are shown in Fig. 3c. Several enzymes related to anthocyanin biosynthesis were more abundant in BRWJ and BREJ than in other cultivars (Fig. 3c). These included phenylalanine ammonia-lyase (PAL2), OsCAD, flavonoid monoxydase, UDP-Glc dehydrogenase (UDP-Glc $\mathrm{DH}), 3$-glycosyltransferase (Os3GT), acyltransferase, cycloartenol 24-C methyltransferase, chalcone isomerase, and UDP-Glc DH5. The predicted biological functions of the 2316 black rice proteins were clustered into 13 categories, including biological phase, cell proliferation, immune system process, metabolic process, multicellular organism process, rhythmic process, developmental process, response to the stimulus, biological regulation, reproduction, localization, nitrogen utilization, cellular component organization or biogenesis, and cellular process. Metabolic and cellular processes were the most common functions of black rice proteins (Fig. 3d).

\section{DISCUSSION}

Genomic profiling of Java black rice plants revealed some specific bands in RM markers, such as RM318, RM224, RM202, RM1369, and RM6364 in case of BRWJ. Furthermore, RM202 showed a specific band in BREJ and RM251 showed specific bands in BRCJ and BREJ samples. RM223 product bands were conserved in the Java black rice cultivars. Fatimah and others (Fatimah et al., 2016) reported that some SSR markers that had high numbers of polymorphic alleles in Indonesian paddy rice were RM162, RM287, RM541, RM144, RM474, and RM171. Another study from Ladjao et al. (2019) revealed that Toraja paddy rice showed high polymorphism in RM259, RM224, RM334, and RM552 products. The different polymorphic patterns of SSR rice markers may be associated with paddy rice traits. For instance, an RM224 pattern was linked to germination rate, shoot dry weight, and shoot length, while the RM223 pattern was related to seed weight, germination rate, shoot length, and seedling early vigor (Anandan et al., 2016). Fukuta and others (Fukuta et al., 2012) mapped RM1369 on chromosome 6 and correlated it with panicle weight in new African (NERICA) rice varieties. The genomic profiling of unique alleles related to specific rice traits in Oryza glaberrima or wild type African rice revealed bands of 170-187 bp in RM250, 117 bp in RM312, and 140- 


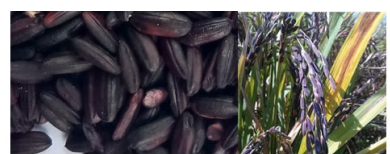

Black Rice

\section{Genomic profiles:}

- SSR profiles proved specific morphological characteristic in each black rice

Rc gene exon 2 had similar sequence on the three black rice cultivars from Java Island

- GT gene of BRWJ showed different sequence than others

\section{Several enzyme related to anthocyanin synthesis is predicted high} expression :

- Phenylalanine ammonia lyase (PAL2)

- Chalcone isomerase (OsCHI)

- Flavonoid monoxydase

- Glycosyltransferase (Os3GT)

- Acyltransferase

Phytochemical Compounds

High phenylalanine, flavonoids, and leucoanthocyanidin

The variety of anthocyanins (Cyanidin, cyanidin-3-O-glucoside, peonidin, peonidin-3-O-glucoside) were established in BREJ and BRWJ

\section{Biological function :}

Antioxidant ${ }^{1}$, Antiobesity ${ }^{2,3}$, Anti-inflammatory ${ }^{4}$

Figure 4. Summary of genomic, proteomic, and anthocyanin profiles in black rice from Java island,

numerical superscripts indicate the data derived from previous studies: '(Fatchiyah et al., 2020a), 2(Fatchiyah et al., 2020b), ${ }^{3}$ (Sari et al., 2020b), ${ }^{4}$ (Sari et al., 2019a).

150 bp in RM223 markers (Chen et al., 2017). Karmakar and others (Karmakar et al., 2012) reported that 10 of 22 studied SSR markers showed unique alleles in the Bengal rice cultivar. The different SSR alleles profile in Java black rice compared to other Asian rice cultivars may reflect adaptation to different environmental factors. The phylogenetic tree of five rice cultivars provided a model of the genetic relationship of these rice cultivars. The clustering of BREJ with WREJ might suggest this white rice is a product of the BREJ black rice domestication process. The domestication process, breeding activities, and landrace condition greatly impact the high similarity coefficient in genetic diversity analysis (Reig-Valiente et al., 2016). The similarity coefficient among the five rice cultivars from Java proved greater than $90 \%$, suggesting that the different cultivars are closely related. Our study revealed that the black rice color was caused by anthocyanin accumulation. Figure 4 shows a summary of the genomic, proteomic and anthocyanin profile components that promote biological activities.

Anthocyanin accumulation in pigmented rice grains is regulated by several genes, such as $R c$ and $G T$ genes. The $R c$ gene encodes a basic helix loop helix (bHLH) protein that interacts with WD40 and MYB protein to form the MYB-bHLH-WD40 (MBW) complex (Albert et al., 2014 and Peña-Sanhueza et al., 2017). The MBW complexes switch on and off the structural genes, including those for enzyme involved in anthocyanidin synthesis (OsPAL, OsCHS, OsC4H, Os4CL, OsCHI, OsF3H, OsF3' $H$, OsANS, OsANR, and OsLDOX), decorating with sugars and methyl groups (Os $3 G T$ and $O s M T$ ), and transporting anthocyanins (OsGST). Our study identified similar sequences of the $\mathrm{R} c$ gene in three black rice cultivars, indicating it has potential to activate anthocyanin synthesis genes. Previous studies revealed that a 14-bp deletion mutation and a transversion $<3 \%$ in exon 7 of the $\mathrm{R} c$ gene inactivated DFR gene expression and resulted in white-pericarp in rice (Sweeney et al., 2006; Maeda et al., 2014; Zhu et al., 2019). Another anthocyanin synthesis gene is the GT gene that encodes a glycosyltransferase that can add sugar to stabilize the anthocyanin structure. Some black rice GT gene mutations might be related to specific morphological characters on BRWJ, which has purple leaves, blades, stems, and grains. Li and others ( $\mathrm{Li}$ et al., 2017a) stated that overexpression of a GT gene implied higher anthocyanin contents in Arabidopsis thaliana. However, GT gene overexpression decreased glycosyltransferase activity and reduced color intensity in Rosa rugosa (Sui et al., 2019).

In the present study, proteomic data identified some transferases in black rice, including proteins with putative methyltransferase, acyltransferase, and glycosyltransferase activities. These transferases may contribute to anthocyanin modifications (Sasaki et al., 2014; Provenzano et al., 2014; Li et al., 2017b; Wang et al., 2018; Sui et al., 2019). We found some proteins related to anthocyanin synthesis with the higher expression in black rice than white rice. Phenylalanine is an amino acid precursor for secondary metabolite synthesis in plants, including that of flavanols and anthocyanins (Cheng et al., 2014). Phenylalanine is processed to leucoanthocyanidin, which is oxidized to cyanidin by leucoanthocyanidin oxidase (LDOX) (Poustka et al., 2007). Fatchiyah and others (Fatchiyah et al., 2020a) described that black rice has higher phenylalanine, flavonoids, and leucoanthocyanidin than red and white rice. Cyanidin is glycosylated to cyanidin-3-O-glucoside by glycosyltransferase (Os3GT), while it is methylated to peonidin by a methyltransferase (Cheng et al., 2014; Provenzano et al., 2014; Olivas-Aguirre et al., 2016; Peng et al., 2017; Zheng et al., 2019b). The acyltransferase in black rice transfers an acyl group to produce more complex anthocyanins (Bontpart et al., 2015). Anthocyanins and proanthocyanidins are synthesized in different pathways. Proanthocyanidins are derived from leucoanthocyanidins and cyanidin through flavan-3-ol (Olivas-Aguirre et al., 2016). Anthocyanins and proanthocyanidins are carried to the vacuole with glutathione-S-transferase (OsGST), serving as their protein transporter (Gomez et al., 2011; Chanoca et al., 2015). Cyanidin-3-O-glucoside and peonidin-3-O-glucoside are the main anthocyanins in black rice (Hou et al., 2013; Pengkumsri et al., 2015; Pedro et al., 2016). Similarly, the present study identified cyanidin 3-O-glucoside in the three kinds of black rice from Java, while other anthocyanins (cyanidin, peonidin, and peonidin-3-O-glucoside) were detected in BREJ F5 and BRWJ F15. The profiles of anthocyanins in black rice from Java might correlate with their biological function.. Fatchiyah and others (Fatchiyah et al., 2020a) reported that BREJ and BRWJ extracts have high total anthocyanins and antioxidant activity. In silico study showed that peonidin-3-O-glucoside may have anti-inflammatory activity via inhibiting TNF- $\alpha$ receptor (Sari et al., 2019a). Cyanidin-3-O-glucoside and peonidin-3-O-glucoside are predicted to have anti-apoptosis effect by inhibiting caspase-3 (Sari et al., 2020a). In vivo and in-silico studies have proven that black rice anthocyanins act against obesity and adipogenesis (Fatchiyah et al., 2020b, Fatchiyah et al., 2020c; Sari et al., 2020b). In the current study, anthocyanins were not detected in RREJ red rice fraction containing pigment. Several studies identified malvidin (Chen et al., 2012) and proanthocyanidin, rather than anthocyanins, as the pigments found in high amounts 
in red rice (Vargas et al., 2018; Laokuldilok et al., 2011; Olivas-Aguirre et al., 2016).

\section{CONCLUSIONS}

Three black rice cultivars demonstrated different genomic, proteomic, and anthocyanin profiles. The SSR profiles identified specific bands in three black rice cultivars. The $R c$ gene exon 2 showed a similar sequence in all black rice cultivars from Java and GT gene demonstrated some mutations and predicted a new variant of the gene in BRWJ cultivar. Proteomic profiles revealed that the levels of proteins related to anthocyanin synthesis varied in black rice cultivars. Black rice Anthocyanin from Java cultivars proved some biological activities and the Java black rice substantiate recommended as a functional food.

\section{Acknowledgements}

The authors thank Dr. Suwadee Chokchaisiri and Istiftakhun Nikmah for anthocyanin purification in the Center for Biomolecular Structure, Function and Application, Suranaree University of Technology, Thailand. We acknowledge SMONAGENES and JKC lab for the discussions and providing the laboratory facilities.

\section{REFERENCES}

Albert NW, Davies KM, Lewis DH, Zhang H, Montefiori M, Brendolise C, Boase MR, Ngo H, Jameson PE, Schwinn KE (2014) A conserved network of transcriptional activators and repressors regulates anthocyanin pigmentation in Eudicots. The Plant Cell 26: 962-980. https://doi.org/10.1105/tpc.113.122069

Anandan A, Anumalla M, Pradhan SK, Ali J (2016) Population structure, diversity and trait association analysis in rice (Oryza sativa L.) germplasm for early seedling vigor (ESV) using trait linked SSR markers. PLOS ONE 11: 1-22. https://doi.org/10.1371/journal. pone.0152406

Anisimovienė N, Jankauskienė J, Jodinskienè M, Bendokas V, Stanys V, Šikšnianas T (2013) Phenolics, antioxidative activity and characterization of anthocyanins in berries of blackcurrant interspecific hybrids. Acta Biochimica Polonica 60: 767-772. https://doi.org/https:// doi.org/10.18388/abp.2013_2055

Azzini E, Giacometti J, Russo GLGL (2017) Antiobesity effects of anthocyanins in preclinical and clinical studies. Oxidative Med Cell Longevity 2017: 1-11. https://doi.org/10.1155/2017/2740364

Bontpart T, Cheynier V, Ageorges A, Terrier N (2015) BAHD or SCPL acyltransferase? What a dilemma for acylation in the world of plant phenolic compounds. New Phytologist 208: 695-707. https:// doi.org/10.1111/nph.13498

Cao PJ, Bartley LE, Jung KH, Ronald PC (2008) Construction of a rice glycosyltransferase phylogenomic database and identification of rice-diverged glycosyltransferases. Molecular Plant 1: 858-877. https://doi.org/10.1093/mp/ssn052

Chanoca A, Kovinich N, Burkel B, Stecha S, Bohorquez-Restrepo A, Ueda T, Eliceiri KW, Grotewold E, Otegui MS (2015) Anthocyanin vacuolar inclusions form by a microautophagy mechanism. Plant Cell 27: 2545-2599. https://doi.org/10.1105/tpc.15.00589

Chen C, He W, Nassirou TY, Nsabiyumva A, Dong X, Adedze YMN, Jin D (2017) Molecular characterization and genetic diversity of different genotypes of Oryza sativa and Oryza glaberrima. Electronic Journal of Biotechnology 30: 48-57. https://doi.org/10.1016/j.ejbt.2017.08.001

Chen X, Itani T, Wu X, Chikawa Y, Irifune K (2013) Physiological factors affecting transcription of genes involved in the flavonoid biosynthetic pathway in different rice varieties. Plant Signaling Behavior 8: 1-8. https://doi.org/10.4161/psb.27555

Chen XQ, Nagao N, Itani T, Irifune K (2012) Anti-oxidative analysis, and identification and quantification of anthocyanin pigments in different coloured rice. Food Chemistry 135: 2783-2788. https://doi. org/10.1016/j.foodchem.2012.06.098

Chen YY, Xu ZS, Xiong AS (2016) Identification and characterization of DcUSAGT1, a UDP-glucose: Sinapic acid glucosyltransferase from purple carrot taproots. PLOS ONE 11: 1-13. https://doi. org/10.1371/journal.pone.0154938

Cheng J, Wei G, Zhou H, Gu C, Vimolmangkang S (2014) Unraveling the mechanism underlying the glycosylation and methylation of Anthocyanins in peach. Plant Physiol 166: 1044-1058. https://doi. org/10.1104/pp.114.246876

Chin HanShiuan, Wu Yong-Pei, Hour AiLing, Hong ChwanYang, Lin YannRong (2016) Genetic and evolutionary analysis of purple leaf sheath in rice. Rice 9: 1-14. https://doi.org/10.1186/s12284-0160080-y

Fatchiyah, Arumningtyas EL, Widyarti S (2011) Biologi molekuler: Prinsip dasar analisis. 2011th edn. Jakarta, Indonesia: Erlangga

Fatchiyah F, Sari DR, Safitri A, Cairns JRK (2020a) Phytochemical compound and nutritional value in black rice from Java Island, Indonesia. Systematic Rev Pharmacol 11: 414-421. https://doi. org/10.31838/srp.2020.7.61

Fatchiyah F, Meidinna HN, Suyanto E (2020b) The cyanidin-3-O-glucoside of Black Rice inhibits the interaction of HMG-CoA and HMG-CoA Reductase: Three-and two-dimension structure. Journal of Physics: Conference Series 1665: https://doi.org/10.1088/17426596/1665/1/012005

Fatchiyah F, Safitri A, Rohmah RN, Triprisila LF, Kurnianingsih N, Nugraha Y, Fajriani S, Meidinna HN, Robert-Cairns JK (2020c) The effect of anthocyanin of whole-grain pigmented rice attenuated visceral fat, cholesterol, LDL and PPAR $\gamma$ gene cascade in dyslipidemia rat. Systematic Reviews in Pharmacy 11: 318-327. https://doi. org/10.31838/srp.2020.10.53

Fatimah F, Lina, Herlina, Sudiaty T, Silitonga (2016) Genetic diversity and trait association analysis of Indonesia rice (Oryza sativa L.) germplasm using SSR markers. Biotropia 23: 105-115. https://doi. org/10.11598/btb.2016.23.2.489

Fukuta Y, Konisho K, Senoo-Namai S, Yanagihara S, Tsunematsu H, Fukuo A, Kumashiro T (2012) Genetic characterization of rainfed upland New Rice for Africa (NERICA) varieties. Breeding Sci 62: 27-37. https://doi.org/10.1270/jsbbs.62.27

Furukawa T, Maekawa M, Oki T, Suda I, Iida S, Shimada H, Takamure I (2006) The Rc and Rd genes are involved in proanthocyanidin synthesis in rice pericarp. Plant J 1: 91-102. https://doi. org/10.1111/j.1365-313X.2006.02958.x

Gomez C, Conejero G, Torregrosa L, Cheynier V, Terrier N, Ageorges A (2011) In vivo grapevine anthocyanin transport involves vesicle-mediated trafficking and the contribution of anthoMATE transporters and GST. Plant J 67: 960-970. https://doi.org/10.1111/ j.1365-313X.2011.04648.x

Himi E, Taketa S (2015) Isolation of candidate genes for the barley Ant1 and wheat Rc genes controlling anthocyanin pigmentation in different vegetative tissues. Mol Genet Genom 290: 1287-1298. https://doi.org/10.1007/s00438-015-0991-0

Hou Z, Qin P, Zhang Y, Cui S, Ren G (2013) Identification of anthocyanins isolated from black rice (Oryza sativa L .) and their degradation kinetics. FRIN 50: 691-697. https://doi.org/10.1016/j. foodres.2011.07.037

Huang Y-P, Lai H-M (2016) Bioactive compounds and antioxidative activity of colored rice bran. J Food Drug Anal 24: 564-574. https:// doi.org/10.1016/J.JFDA.2016.01.004

Karmakar J, Roychowdhury R, Kar RK, Deb D, Dey N (2012) Profiling of selected indigenous rice (Oryza sativa L.) landraces of Rarh Bengal in relation to osmotic stress tolerance. Physiol Mol Biol Plants 18: 125-132. https://doi.org/10.1007/s12298-012-0110-1

Kong S, Kim DJ, Oh SK, Choi IS, Jeong HS, Lee J (2012) Black rice bran as an ingredient in noodles: chemical and functional evaluation. J Food Sci 77: https://doi.org/10.1111/j.1750-3841.2011.02590.x

Ladjao HE, Sjahril R, Riadi M (2019) Keragaman Genetik 22 Aksesi Padi Lokal Toraja Utara Berbasis Marka Simple Sequence Repeats (SSR). Jurnal Bioteknologi \& Biosains Indonesia (JBBI) 5: 230. https:// doi.org/10.29122/jbbi.v5i2.3031

Laokuldilok T, Shoemaker CF, Jongkaewwattana S, Tulyathan V (2011) Antioxidants and antioxidant activity of several pigmented rice brans. J Agricul Food Chemi 59: 193-199. https://doi.org/10.1021/ if103649q

Li D, Wang P, Luo Y, Zhao M, Chen F (2017a) Health benefits of anthocyanins and molecular mechanisms: Update from recent decade. Crit Revi Food Sci Nutrit 57: 1729-1741. https://doi.org/10.1080/10 408398.2015.1030064

Li P, Li YJ, Zhang FJ, Zhang GZ, Jiang XY, Yu HM, Hou BK (2017b) The Arabidopsis UDP-glycosyltransferases UGT79B2 and UGT79B3, contribute to cold, salt and drought stress tolerance via modulating anthocyanin accumulation. Plant J 89: 85-103. https:// doi.org/10.1111/tpj.13324

Li X-Yan, Qiang S, Song X Ling, Cai K, Sun Y Na, Shi Z Hua, Dai W Min (2014) Allele types of rc gene of weedy rice from Jiangsu Province, China. Rice Sci 21: 252-261. https://doi.org/10.1016/ S1672-6308(13)60183-3

Liu Z, Li J, Sun Y, Zhang P, Wang Y (2020) Structural insights into the catalytic mechanism of a plant diterpene glycosyltransferase SrUGT76G1. Plant Commun 1: 100004. https://doi.org/10.1016/j. xplc.2019.100004

Luang S, Cho J Il, Mahong B, Opassiri R, Akiyama T, Phasai K, Komvongsa J, Sasaki N, Hua YL, Matsuba Y, Ozeki Y, Jeon JS, Cairns JRK (2013) Rice Os9BGlu31 is a transglucosidase with the 
capacity to equilibrate phenylpropanoid, flavonoid, and phytohormone glycoconjugates. J Biol Chem 288: 10111-10123. https://doi. org/10.1074/jbc.M112.423533

Maeda H, Yamaguchi T, Omoteno M, Takarada T, Fujita K, Murata K, Iyama Y, Kojima Y, Morikawa M, Ozaki H, Mukaino N, Kidan Y, Ebitani T (2014) Genetic dissection of black grain rice by the development of a near isogenic line. Breeding Sci 64: 134-141. https://doi.org/10.1270/jsbbs.64.134

Maksup S, Pongpakpian S, Roytrakul S, Cha-um S, Supaibulwatana K (2017) Comparative proteomics and protein profile related to phenolic compounds and antioxidant activity in germinated Oryza sativa 'KDML105' and Thai brown rice 'Mali Dang' for better nutritional value. J Sci Food Agric 98: 566-573. https://doi.org/10.1002/ jsfa. 8498

Montefiori M, Espley R V., Stevenson D, Cooney J, Datson PM, Saiz A, Atkinson RG, Hellens RP, Allan AC (2011) Identification and characterisation of F3GT1 and F3GGT1, two glycosyltransferases responsible for anthocyanin biosynthesis in red-fleshed kiwifruit (Actinidia chinensis). Plant J 65: 106-118. https://doi.org/10.1111/ j.1365-313X.2010.04409.x

Moon S, Kim S-R, Zhao G, Yi J, Yoo Y, Jin P, Lee S-W, Jung K, Zhang D, An G (2013) Rice GLYCOSYLTRANSFERASE1 Encodes a glycosyltransferase essential for pollen wall formation. Plant Physiol 161: 663-675. https://doi.org/10.1104/pp.112.210948

Nakatsuka T, Sato K, Takahashi H, Yamamura S, Nishihara M (2008) Cloning and characterization of the UDP-glucose:anthocyanin 5-Oglucosyltransferase gene from blue-flowered gentian. J Exp Bot 59: 1241-1252. https://doi.org/10.1093/jxb/ern031

Olivas-Aguirre FJ, Rodrigo-García J, Martínez-Ruiz NDR, CárdenasRobles AI, Mendoza-Díaz SO, Ảlvarez-Parrilla E, González-Aguilar GA, De La Rosa LA, Ramos-Jiménez A, Wall-Medrano A (2016) Cyanidin-3-O-glucoside: Physical-chemistry, foodomics and health effects. Molecules 21: 1-30. https://doi.org/10.3390/molecules 21091264

Park JR, Yang W'T, Kwon YS, Kim HN, Kim KM, Kim DH (2019) Assessment of the genetic diversity of rice germplasms characterized by black-purple and red pericarp color using simple sequence repeat markers. Plants 8: 1-12. https://doi.org/10.3390/plants8110471

Pedro AC, Granato D, Rosso ND (2016) Extraction of anthocyanins and polyphenols from black rice (Oryza sativa L.) by modeling and assessing their reversibility and stability. Food Chem 191: 12-20. https://doi.org/10.1016/j.foodchem.2015.02.045

Peña-Sanhueza D, Inostroza-Blancheteau C, Ribera-Fonseca A, ReyesDíaz M (2017) Anthocyanins in Berries and Their Potential Use in Human Health. Superfood and Functional Food - The Development of Superfoods and Their Roles as Medicine https://doi.org/10.5772/67104

Pengkumsri N, Chaiyasut C, Saenjum C, Sirilun S, Peerajan S, Suwannalert P, Sirisattha S, Sivamaruthi BS (2015) Physicochemical and antioxidative properties of black, brown and red rice varieties of northern Thailand. 35: 331-338.

Phonsakhan W, Kong-Ngern K (2015) A comparative proteomic study of white and black glutinous rice leaves. Electronic I Biotechnol 18: 29-34. https://doi.org/http://dx.doi.org/10.1016/j.ejbt.2014.11.005

Poustka F, Irani NG, Feller A, Lu Y, Pourcel L, Frame K, Grotewold E (2007) A trafficking pathway for anthocyanins overlaps with the endoplasmic reticulum-to-vacuole protein-sorting route in Arabidopsis and contributes to the formation of vacuolar inclusions. Plant Physiol 145: 1323-1335. https://doi.org/10.1104/pp.107.105064

Prasad BJ, Sharavanan PS, Sivaraj R (2019) Health benefits of black rice - A review. Grain Oil Sci Technol 2: 109-113. https://doi. org/10.1016/j.gaost.2019.09.005

Priya, Sathyan Sri Lavvanya; Devi, Ponnusamy Renuka; Eganathan PK, Jayasurya (2013) In vitro antimicrobial activity of Syzygium cumini fruit peel and identification of anthocyanins. African J Pharm Pharmacol 7: 1719-1728. https://doi.org/10.5897/ajpp12.1306

Provenzano S, Spelt C, Hosokawa S, Nakamura N, Brugliera F, Demelis L, Geerke DP, Schubert A, Tanaka Y, Quattrocchio F, Koes R (2014) Genetic control and evolution of anthocyanin methylation. Plant Physiol 165: 962-977. https://doi.org/10.1104/pp.113.234526

Reig-Valiente JL, Viruel J, Sales E, Marqués L, Terol J, Gut M, Derdak S, Talón M, Domingo C (2016) Genetic diversity and population structure of rice varieties cultivated in temperate regions. Rice $\mathbf{9}$ https://doi.org/10.1186/s12284-016-0130-5

Samyor D, Das AB, Deka SC (2017) Pigmented rice a potential source of bioactive compounds: a review. Int J Food Sci Technol 52: 10731081. https://doi.org/10.1111/ijfs.13378

Sari DRT, Cairns JRK, Safitri A, Fatchivah F (2019a) Virtual prediction of the delphinidin-3-o-glucoside and peonidin-3-o-glucoside as anti-inflammatory of TNF- $\alpha$ signaling. Acta Informatica Medica 27: 152-157. https://doi.org/10.5455/aim.2019.27.152-157

Sari DRT, Safitri A, Cairns JRK, Fatchivah F (2019b) Protein profiling of coloring rice (Oryza sativa L.) using SDS-PAGE and expe- rion ${ }^{\mathrm{TM}} 260$ analysis. J Physics: Conference Series 1146: 7. https://doi. org/10.1088/1742-6596/1146/1/012038

Sari DRT, Safitri A, Cairns JRK, Fatchiyah F (2020a) Anti-apoptotic activity of anthocyanins has potential to inhibit caspase- 3 signaling. J Tropical Life Sci 10: 15-25. https://doi.org/10.11594/jtls.10.01.03

Sari DRT, Safitri A, Cairns JRK, Fatchiyah F (2020b) Virtual screening of black rice anthocyanins as antiobesity through inhibiting TLR4 and JNK pathway. J Physics: Conference Series 1665: https://doi. org/10.1088/1742-6596/1665/1/012024

Sasaki N, Nishizaki Y, Ozeki Y, Miyahara T (2014) The role of acylglucose in anthocyanin modifications. Molecules 19: 18747-18766. https://doi.org/10.3390/molecules191118747

Shen C-H (2019) Quantification and analysis of proteins. Diagnostic Mol Biol 187-214. https://doi.org/10.1016/b978-0-12-802823-0.00008-0

Sivamaruthi BS, Kesika P, Chaiyasut C (2018) Anthocyanins in Thai rice varieties: Distribution and pharmacological significance. Int Food Res J 25: 2024-2032

Sui X, Zhao M, Han X, Zhao L, Xu Z (2019) RrGT1, a key gene associated with anthocyanin biosynthesis, was isolated from Rosa rugosa and identified via overexpression and VIGS. Plant Physiol Biochem 135: 19-29. https://doi.org/10.1016/j.plaphy.2018.11.022

Sun W, Liang L, Meng X, Li Y, Gao F, Liu X, Wang S, Gao X, Wang L (2016) Biochemical and molecular characterization of a flavonoid 3-O-glycosyltransferase responsible for anthocyanins and flavonols biosynthesis in Freesia bybrida. Frontiers Plant Sci 7: 1-14. https://doi. org/10.3389/fpls.2016.00410

Sweeney Megan T, Thomson Michael J, Pfeil BE, McCouch S (2006) Caught Red Handed: Rc encodes a basic helix loop helix protein conditioning red pericarp in rice. The Plant Cell 18: 283-294. https://doi.org/10.1105/tpc.105.038430.1

Thompson K, Pederick W, Santhakumar AB (2016) Anthocyanins in obesity-associated thrombogenesis: A review of the potential mechanism of action. Food Function 7: 2169-2178. https://doi. org/10.1039/c6fo00154h

Tyanova S, Temu T, Carlson A, Sinitcyn P, Mann M, Cox J (2015) Visualization of LC-MS/MS proteomics data in MaxQuant. Proteomics 15: 1453-1456. https://doi.org/10.1002/pmic.201400449

Vargas CG, da Silva Junior JD, Rabelo TK, Moreira JCF, Gelain DP, Rodrigues E, Augusti PR, Rios A de O, Flôres SH (2018) Bioactive compounds and protective effect of red and black rice brans extracts in human neuron-like cells (SH-SY5Y). Food Research International 113: 57-64. https://doi.org/10.1016/j.foodres.2018.06.069

Wang H, Wang C, Fan W, Yang J, Appelhagen I, Wu Y, Zhang P (2018) A novel glycosyltransferase catalyses the transfer of glucose to glucosylated anthocyanins in purple sweet potato. J Exp Bot 69: 5445-5459. https://doi.org/10.1093/jxb/ery305

Wang N, Wu X, Ku L, Chen Y, Wang W (2016) Evaluation of three protein-extraction methods for proteome analysis of maize leaf midrib, a compound tissue rich in sclerenchyma cells. Frontiers Plant Sci 7: 1-12. https://doi.org/10.3389/fpls.2016.00856

Xu W, Dubos C, Lepiniec L (2015) Transcriptional control of flavonoid biosynthesis by MYB-bHLH-WDR complexes. Trends Plant Sci 20: 176-185. https://doi.org/10.1016/j.tplants.2014.12.001

Yan F, Zheng X (2017) Anthocyanin-rich mulberry fruit improves insulin resistance and protects hepatocytes against oxidative stress during hyperglycemia by regulating AMPK/ACC/mTOR pathway. J Functional Foods 30: 270-281. https://doi.org/10.1016/j. jff.2017.01.027

Zaidi SHR, Zakari SA, Zhao Q, Khan AR, Shah JM, Cheng F (2019) Anthocyanin accumulation in black kernel mutant rice and its contribution to ROS detoxification in response to high temperature at the filling stage. Antioxidants 8: 510. https://doi.org/10.3390/antiox 8110510

Zhang QW, Lin LG, Ye WC (2018) Techniques for extraction and isolation of natural products: A comprehensive review. Chinese Medicine (United Kingdom) 13: 1-26. https://doi.org/10.1186/s13020-0180177-x

Zheng J, Wu H, Zhu H, Huang C, Liu C, Chang Y, Kong Z, Zhou Z, Wang G, Lin Y, Chen H (2019a) Determining factors, regulation system, and domestication of anthocyanin biosynthesis in rice leaves. New Phytologist 223: 705-721. https://doi.org/10.1111/ nph.15807

Zheng J, Wu H, Zhu H, Huang C, Liu C, Chang Y, Kong Z, Zhou Z, Wang G, Lin Y, Chen H (2019b) Determining factors, regulation system, and domestication of anthocyanin biosynthesis in rice leaves. New Phytologist 223: 705-721. https://doi.org/10.1111/ nph.15807

Zhu Y, Lin Y, Chen S, Liu H, Chen Z, Fan M, Hu T, Mei F, Chen J, Chen L, Wang F (2019) CRISPR/Cas9-mediated functional recovery of the recessive rc allele to develop red rice. Plant Biotechnol J 17: 2096-2105. https://doi.org/10.1111/pbi.13125 